\title{
Economists in the Insurance Industry
}

\author{
by Wlodek Zajdlic *
}

\section{Introduction}

The main purpose of this paper is to comment on the role played by professional economists in the insurance industry. This role is seen here as a still unfolding evolutionary process born of the sudden appearance of economic risks and entering a new stage of full-scale participation in insurance planning. As it will be obvious from the text, the whole process has only just started and it is for this very reason that an informed discussion of the issues at stake is necessary so as to avoid the many pitfalls which may be costly to the industry.

The paper falls into three parts. The first part traces the entry of professional economists into the insurance industry back to the sudden appearance, in the early $70 \mathrm{~s}$, of purely economic risks with which the industry had to cope. At this stage, the economists, due to various obstacles inherent in the novelty of their task, are being given an advisory (rather peripheral) status within the administrative structure of the industry. Part two reviews briefly a general case for the introduction of planning techniques as an aid to policy formulation. Part three analyses, in some detail, the nature of economists' participation in insurance planning. It is only at this stage that economists can expect to become fully integrated into the policy formulation processes of the industry.

\section{The emergence of economic risks}

It is normally difficult to define with any precision the timing of any industrial phenomenon. Yet, in our case, it can be safely asserted that before 1970, the insurance industry in the West did not employ economists in their professional capacity on a full-time basis. Of course, economists existed but only in a disguised capacity of investment managers, staff officers, secretaries, etc. This position changed drastically in the early 70 s due to a sudden intrusion of powerful purely economic factors of inflation, exchange fluctuations and state intervention. The impact of these factors has given birth to a unique phenomenon of economic risks with which the existing policymaking machinery of the industry was ill-equipped to cope. What really mattered was both the magnitude and degree of change introduced by these risks. For instance, inflation was not a new phenomenon but, whereas its annual average rate for total OECD stood at $3.4 \%$ during the $60 \mathrm{~s}$, it suddenly rose to $13.6 \%$ in 1974 and fell to $8.6 \%$ two years later. ${ }^{1}$

There is no doubt as to the shattering effects of such changes on insurance claims, premium income, and solvency margins. Much the same lesson was painfully learned

\footnotetext{
* Senior Political Economist, " Commercial Union".

1 Sources: "OECD Economic Outlook", December 1973, p. 35 and December 1977, p. 54 .
} 
by the British Insurance Industry in 1976 when the collapse of the exchange rate of the pound squeezed the solvency margins of British companies operating extensively abroad. Without going into details, it is sufficient to stress that both inflation and exchange rate fluctuations have had a powerful detrimental effect on the indusry's running costs, claims, premium and capital base. There is little doubt that these effects are quite capable of more than offsetting even technically perfect underwriting decisions. Apart from inflation and exchange rate fluctuations, increasing state intervention had added fresh difficulties in the shape of extensive controls over premium, employment, investment, state of reserves, transferrability of profits, etc. In addition, all these factors powerfully affect growth and employment, thus having a direct bearing on the volume of insurance business and its profitability.

The above economic factors also affect normal underwriting risks. Thus, inflation may easily lead to the use of inferior raw materials thereby accelerating machinery breakdowns; whereas its unemployment-stimulating effect may easily increase social violence with consequent results of rising theft, destruction of both public and private property, etc.

This short passage should be sufficient to show the vast scope of influence that economic factors have on the fortunes of insurance industry. Obviously, the degree of this influence increases sharply as soon as an insurance company extends its activities to foreign risks, because of the immediate effects of exchange fluctuations on foreign cost, premium income and solvency margins.

If the magnitude of economic effects is non-controversial so is, by definition, the competence of professional economists to tackle the twin task of analysing economic factors and relating them to the needs of the insurance industry. In this respect, however, the economists have come across a number of very important obstacles.

1. The industry's own vagueness regarding the modus operandi of economic factors should perhaps head the list. This is partly a product of inadequate theoretical preparation and partly of the novelty of the impact of economic factors. As for the former it will perhaps suffice to point out that the basic insurance textbook used in the U.K., "Legal and Economic Aspects of Insurance" (CII Tuition Service), omits completely both the macro and international aspects of economic activities, which happen to represent the main sources of economic disturbance that currently affects the insurance industry. This factor, coupled with the previously discussed novelty of economic influences, will make the task of communication between economists and insurance practitioners very difficult.

2. Connected with the above is the lack of a comprehensive theoretical framework of insurance economics. Of particular relevance here, is the lack of theoretical formulation of : cyclical response of the insurance industry to national and international fluctuations of growth, and inflation; insurance effects of unemployment, capital scarcity, forms of competition on international and national markets, interdependence with other financial institutions, relationship with the state, etc.

3. The above theoretical background might be easier to complete were it not for the lack of relevant statistical material. This is specially true of the international aspect of this problem for, although it is possible to assemble basic national insurance statistics, it is not possible to arrive at a meaningful international picture due to 
important differences in definitions, basis and coverage. Even national statistics, compiled usually for the convenience of domestic fiscal authorities, are unduly restrictive in scope and do not, as a rule, go far enough in time.

4. Another difficulty arises because of the complex structure of the industry itself divided into broking, reinsurance and direct underwriting sectors, each of which, in turn, may vary according to the scope of its activities being either domestic, or international, and concentrated on either life or non-life business. It is these factors which will primarily determine the applicability of economists serving a given insurance sector.

5. Closely related to the above is the unending variety of forms of competition represented by each particular insurance market. This is an important factor circumscribing the scope of policy initiative by any particular company.

6. Confusion regarding the interpretation of the term "political risk" constitutes another difficulty. Nominally, the term derives its origin from intervention of the state in the domestic economy. This intervention is nowadays so intensive and ubiquitous that, without at least a basic distinction between its direct and indirect aspects (e.g. a particular subsidy to a firm/ industry as contrasted with incomes policy), the concept of political risk becomes very tenuous indeed, ranging from global war and street brawls to incomes policy and exchange controls. With the range of the political risk being so wide it become very difficult to apportion the responsibility for its analysis. Yet, despite confusing semantics, it is obvious that no matter what its motivation, it is principally the economic consequences of state intervention that the insurance industry is concerned about. Also motivation of this intervention is in the majority of cases economic. ${ }^{2}$

This brief survey is sufficient to emphasise the difficulties under which professional economists operate within the insurance industry. It is the existence of these difficulties that accounts for an administratively undetermined, "advisory" status of economists in the insurance industry. Yet, clearly, such a half-way position cannot be maintained for much longer for there is ample evidence that the influence of economic factors on the industry is only likely to intensify in the future. Consequently, economists must be sooner or later fully integrated into the normal decision-making process of the industry. Increasing interest in planning shown recently by the insurance industry already points this way.

\section{The case for planning in insurance}

Planning as a method of policy determination has recently made progress in insurance, as much as in any other industry, because of profound changes both in the market structure and the pattern of supply and demand facing the industry.

Though, theoretically, the market structure belongs to the demand side of economic equation, its special character deserves a separate mention. The term "special character"

2 For examples of this conceptual confusion see: "Political Risk" by J. Radcliffe in "Insurance Monitor" of $28 / 8 / 75$, and "The Scope of Political Risks" by legal correspondent of "Law and Reinsurance" of June 1976. 
refers here to the modus operandi of the London market which, until very recently, uniquely approximated to the theoretical model of "perfect market". The meaning of this concept lies in an unlimited availability of business for anyone able to underwrite on the market's terms.

It is true that at present London is still the world's largest single insurance, especially reinsurance, market but its leading role is being continuously challenged and eroded by a number of competitive factors. Of these the relative rise of new hard currency centres, often based on extensive technical facilities (such as the Japanese insurance school, or Munich-Re technical schooling facilities) should be mentioned. The hard currency base, true of the German, Swiss and Japanese competitors, means not only increased growth potential (via increased hard currency capital base relative to premium income in depreciating foreign currencies) but also reduced burden of spending in foreign currencies on agencies, brokerage, advertising abroad, etc. By contrast, the catastrophic collapse of the pound in 1976 very painfully reminded the London market of the penalties imposed by the weak currency.

Competition based on weak currencies has also increased. Insofar as the Third World is concerned, it has almost completely driven the Western companies out of domestic markets in these parts of the world. It is true that internal weakness of domestic insurance has resulted in a rapid growth of reinsurance coming from these countries onto the London market. This places, however, on the reinsurers, the burdens of increased exchange exposure, of the need to keep an eye on the development of both risk and underwriting environment in those countries and of the task of finding adequate reciprocity. In addition, the quest for strong currencies has forced some of these countries, especially the Communist countries of Eastern Europe, to compete with Western insurers on the latter's international markets, for instance in the marine market.

To complete the picture, one should also mention the new American Lloyd's which, despite its delayed birth, cannot be dismissed lightly.

Thus, the fourfold threat consisting of : increasing technical competence, existence of hard currency insurers, specific burdens of reinsurance and growing domestication of "weak currency" markets (not to mention the ambivalent long-term prospects of the pound), make the London market less reliable as a long-term source of international insurance business.

Of the remaining factors on the demand side, two other main factors deserve a special note : the emergence of big and new risks. The former refer to such objectives as oil rigs, atomic installations, turn-key factories, etc. Underwriting in this field presupposes the possession of a high level of technological expertise, large technical reserves, and good knowledge of economic underwriting environment ; the last refers to financial reliability of the domestic insurer and government, trends in domestic inflation, growth, balance of payments, etc. The expression "new" risks relates to various risks borne out of the rising interest in consumer and/or environmental protection. Both product and professional liability insurance may be quoted as examples. What is characteristic of these risks is their lack of statistical precedent and vulnerability to social inflation - a particularly volatile species originating in the lawyers' wilful or genuine ignorance of the phenomenon of inflation.

On the supply side two elements seem of primary importance ; the cost of factors of production, that is, labour and capital, and their growing immobility. 
The cost of factors of production bears a firm stamp of inflation and insofar as one can see, this cost is only likely to rise. Apart from inflation, the increasing requirements of specialisation, noted above, and trade union pressure will further stimulate the upward trend of labour cost. Capital cost will also be subject to general inflationary pressure, but in addition the insurance sector will have to compete for scarce capital resources with a far more profitable banking sector and the state. Yet, all the time, the solvency margin will, under the combined pressure of inflation and exchange fluctuations, require repeated additions to capital base.

Considerations of mobility will also require much attention. For nowadays, one has to think twice before pulling out of a country because a chance of readmission is very slim indeed. For identical reasons, the decision to obtain a foothold in a foreign country must be taken on the basis of extensive research concerning both the domestic insurance market and its economic and political underwriting environment. Similar difficulties beset an intention to change the business pattern because of the necessity to obtain enough expertise and dispose of redundant staff.

In a word, the case for adopting planning as a means of policy formulation arises from a combination of increasingly severe penalties imposed by the failure to realise the decisive role played in insurance by the changing market environment.

Ultimately, this factor will win the day for planning but the progress is bound to be slow for several reasons.

Firstly, there is the inertia factor of traditional attitudes borne out of long years of comparative market freedom, and absence of economic, political and social constraints.

Secondly, as the novelty of the planning experiment suggests, neither the conceptual basis for planning nor skilled planning staff are available. In both respects we are at an early pioneering stage.

Thirdly, as previously mentioned, the insurance industry represents a bewildering diversity of structure and interests. This makes it impossible to simplify an approach to planning by evolving a general blue-print for the industry as a whole.

Fourthly, before meaningful planning can be organised, there is vast preliminary work to be done in tracing the lines of interdependence between operational variables of insurance and their economic underwriting environment.

\section{Economists in insurance pianning}

Thus, in theory anyway, economists find themselves in the avant-garde of the planning venture. The exact scope of their participation in planning will, of course, be determined by the nature of market interest of each particular insurance enterprise. Therefore, in agreement with what was said before on this subject, no generally valid prescription as to the role of economists will be attempted here. Instead, a broad assumption is proposed to the effect that the subject will be discussed from the point of view of an insurance company possessing a wide network of international interests in both life and non-life fields. A second broad assumption made here refers to the satisfactory internal integration of economists within the administrative, operational 
and managerial structure of the company. This is a necessary precondition for no planning can be successful without an unimpeded flow of mutual consultation between economists and other staff members of the company.

Given the above assumptions, it is proposed here to base the planning framework on a customary threefold time division into long, medium and short run. The exact quantification of this division will, of course, vary with the requirements of a particular company and the nature of transactions. At the same time, it is postulated here that planning will deal with the two main aspects of the company's activities : financial and insurance proper. The distinction is valid insofar as it presupposes important differences in the economic input into planning and, very often, a different mode of analysis. On the whole, it seems that this distinction will become more pronounced the shorter is the planning period under consideration.

In the long-term, defined here as a time period of minimum five years, there seems to exist a rather close interdependence between financial and pure insurance interests of the company. This interdependence stems from the existence of the common problem which lies in the necessity to change, from time to time, the deployment pattern of the company's resources as between territories and/or lines of business. Insofar as economists are concerned such plans would require a thorough background research into prospective supplies of staff and capital, on the one hand, and the relative potential of new markets, on the other. Economic analysis employed here would most likely remain restricted to macro-economic variables such as : rates of growth of GNP (national and, if available, regional), rates of changes in productivities associated with the above, labour force (including demographic changes, organisation, etc.), savings (its amount and terms of availability to private sector), and government's economic policy in general, and with regard to the private sector, in particular. The latter item must also take into account governmental attitudes towards foreign participation. The above general, macro-economic enquiry should also produce basic material for more specific research into exchange rate and investment trends. Of course, other specific research in respect of, for instance, capital markets, building activities, risk management prospects can also emerge from the same general research basis.

The medium-term planning, dealing with the period of about two to five years, would differ from its long-term counterpart because of the need for an independent formulation of financial and pure insurance plans, and for disaggregation of macroeconomic data with the view of relating them to the main insurance sectors. The former reature is really self-explanatory because of the necessity to relate the general long-term enquiries to specific financial objectives in the fields of exchange exposure and investment finance. At this stage, therefore, it will become necessary for the economists to develop analytical techniques for making longer-term exchange forecasts, and for investigating particular investment yields obtained on different national markets while taking into account different national exchange control and tax regimes. It is a sine qua non condition that, at this stage, constant interchange of information between economists and operating financial departments must be fully established.

Exactly the same condition should be fulfilled in respect of the second feature of medium-term planning, that is, disaggregation of the relevant macro-economic aggregates (mainly national rates of growth and inflation) and matching them with particular insurance sectors. It must be added here that for some sectors of insurance 
business, namely those operating in the international markets, such as marine and aviation, special economic indicators, such as terms of trade, volume growth of international trade, etc. will be required.

The short-run analysis, understood here as one embracing the next two year period, is expected to put maximum emphasis on exact quantification of forecast in both financial and pure insurance fields and further extension of its range. Thus, the participation of economists would not change substantially in comparison with their contribution described previously.

There is, however, one important exception. This stems from the fact that planning as decribed so far is in danger of being only vaguely related to current insurance operations. In order to link them up closely, it is proposed here to introduce the concept of market share of the company. The term is taken here as referring to the share in the total insurance market of a given country divided both into main regions and branches of insurance business, e.g. life, fire, etc. It must be stressed that the concept of market share is to be used as an analytical tool of planning only and not as a business objective which is normally maximisation of profit. Thus applied, the concept of market share seems useful for a number of reasons.

Firstly, it gives a general idea of structural trends in the market's total demand for various classes of insurance. This allows for a quantifiable study of consistency between the company's and market's business structure. Such a comparison is a useful indicator of desirability, or otherwise, of contemplating changes in the existing deployment of the company's assets (meaning both staff and capital resources) on a given market. This contribution refers principally to the planning of both long- and medium-term commercial strategy of the firm.

Secondly, in the short-term, the emphasis should be put on a change in this share. This would serve the purpose of checking the consistency of planning with current operations. The resulting dialogue between the planners and operational management would give the top management a better view of market reality and feasibility of planning objectives.

Thirdly, after a time, a useful dossier of the market's institutional peculiarities could be completed; a very useful addition to purely economic analysis.

It will be noted that the market share type of approach applies only to the insurance sector. In the financial sector the analyses will remain focused on the trends of particular variables, such as chosen interest or exchange rates.

\section{Conclusions}

The emergence of economists in the insurance industry is only a symptom of a profound change in the market reality which the industry, especially in the U.K. with its worldwide ramifications of business interests, is facing now. This change, brought about by a sudden appearance of purely economic aspects of insurance activities, links up firmly the insurance proper with solely financial operations of the industry. It also widens very considerably both the range of factors relevant to underwriting and overall policy decisions and extends the time dimension of business analysis. It is this complexity of the background to the decision-making process that is responsible for a growing trend towards corporate planning within which economists have a vital role to play. 